\title{
Physician Recommendation and Patient Adherence for Colorectal Cancer Screening
}

\author{
Shawna V. Hudson, PhD, Jeanne M. Ferrante, MD, MPH, \\ Pamela Obman-Strickland, PhD, Karissa A. Hahn, MPH, Eric K. Shaw, PhD, \\ Jennifer Hemler, MA, and Benjamin F. Crabtree, PhD
}

Background: Physician recommendation is one of the strongest, most consistent predictors of colorectal cancer (CRC) screening. Little is known regarding characteristics associated with patient adherence to physician recommendations in community and academic based primary care settings.

Methods: Data were analyzed from 975 patients, aged $\geq 50$ years, recruited from 25 primary care practices in New Jersey. Chi-square and generalized estimate equation analyses determined independent correlates of receipt of and adherence to physician recommendation for CRC.

Results: Patients reported high screening rates for CRC (59\%). More than three fourths of patients reported either screening or having received a screening recommendation $(82 \%)$. Men $(P=.0425)$, nonsmokers $(P=.0029)$, and patients who were highly educated $(P=.0311)$ were more likely to receive a CRC screening recommendation. Patients more adhere to CRC screening recommendations were older adults $(P<.0001)$, nonsmokers $(P=.0005)$, those who were more highly educated $(P=.0365)$, Hispanics $(P=.0325)$, and those who were married $(P<.0001)$.

Conclusions: Community and academic primary care clinicians appropriately recommended screening to high-risk patients with familial risk factors. However, they less frequently recommended screening to others (ie, women and smokers) also likely to benefit. To further increase CRC screening, clinicians must systematically recommend screening to all patients who may benefit. ( $\mathrm{J}$ Am Board Fam Med 2012;25:782-791.)

Keywords: Colon/Colorectal Cancer Screening, Community Medicine, Physician/Patient Interaction, Practice-Based Research, Prevention/Screening

Colorectal cancer (CRC) is the third leading cause of new cancer cases and deaths from cancer in the United

This article was externally peer reviewed.

Submitted 24 August 2011; revised 30 June 2012; accepted 9 July 2012.

From The Cancer Institute of New Jersey (SVH, JMF, PO-S, JH, BFC) and the Department of Family Medicine and Community Health (SVH, JMF, PO-S, KAH, EKS, BFC), UMDNJ-Robert Wood Johnson Medical School, New Brunswick; and the Biometrics Division, UMDNJSchool of Public Health, Piscataway, NJ (PO-S).

Funding: This research was supported through grants from the National Cancer Institute (K05 CA140237, K01 CA131500 and R01 CA112387). This research was conducted in conjunction with the New Jersey Primary Care Research Network, a shared resource of the Cancer Institute of New Jersey. It was also supported by the Cancer Institute of New Jersey's Survey Research and Qualitative Methods Shared Resource.

Conflict of interest: none declared.

Corresponding author: Shawna V. Hudson, $\mathrm{PhD}$, The Cancer Institute of New Jersey, 195 Little Albany Street, New Brunswick, NJ 08903 (E-mail: hudsonsh@umdnj.edu).
States $^{1-4}$ with an estimated 143,460 new cases and 51,690 deaths occurring in 2012. ${ }^{3}$ Preventive screening for CRC (eg, colonoscopy, sigmoidoscopy and fecaloccult blood testing [FOBT]) has been shown to reduce mortality in randomized controlled trials and casecontrolled studies. ${ }^{5,6}$ However, screening for CRC remains $l^{4}{ }^{4,7}$ with only $39 \%$ of CRC cases detected at an early, localized stage. ${ }^{1}$

Physician recommendation is one of the most significant predictors of CRC screening. ${ }^{8-11}$ Numerous studies have focused on factors that affect physician recommendation and screening adherence. For example, a number of studies have found that the type of screening modality (eg, colonoscopy vs FOBT) recommended to patients is mediated by demographic factors such as age, race, and sex. ${ }^{8,11-16}$ Physicians are also less likely to recommend CRC screening to particular groups of patients, ${ }^{11,17-19}$ including those with chronic diseases, ${ }^{20}$ lower levels of educa- 
tion, ${ }^{11,12}$ lower socioeconomic status, ${ }^{8}$ and the uninsured. ${ }^{8,12}$ In addition, psychosocial factors in physician recommendation have been identified. For example, physicians are less likely to recommend CRC screening to patients who lack knowledge about the risks and benefits ${ }^{21,22}$ or who have refused in the past. ${ }^{23,24}$

Increasing physician recommendations has been the focus of targeted interventions and research, ${ }^{23,25-30}$ yet few studies specifically investigate differences in patients who receive recommendations for screening versus those who adhere to physician recommendations for CRC screening. ${ }^{8,11,18,20,31}$ Studies that report adherence to particular CRC screening modalities show that sigmoidoscopy and colonoscopy have higher adherence rates than FOBT. ${ }^{8,11}$ The current study explores the gap between recommendation and adherence focusing on patients in community and academic primary care practices. Our research question focuses on identifying patient populations that are not being adequately addressed in terms of CRC screening. Our objective is to aid physicians and their practices in identifying patient populations that could benefit from further attention to CRC screening, increasing the number of patients who are up to date with screening.

\section{Methods}

We conducted a secondary analysis of cross-sectional data collected at baseline and Year 1 from January 2006 through December 2008 from a quality improvement intervention study, Supporting Colorectal Cancer Outcomes through Participatory Enhancements (SCOPE). The SCOPE study used a multimethod assessment process ${ }^{32}$ to inform a facilitated team-building intervention ${ }^{33}$ aimed at improving guideline adherence for preventive cancer screening among 25 community and academic primary care practices in New Jersey. The University of Medicine and Dentistry of New JerseyRobert Wood Johnson Medical School Institutional Review Board approved this study. Written informed consent to participate in the study was received from the medical directors and/or lead physicians of each practice as well as from patients and staff members who participated in the study.

\section{Data Collection}

Clinical outcome data were collected by patient survey and medical record review. Thirty consecu- tive patients $\geq 50$ years of age were recruited in the waiting rooms of each practice. We recruited 1437 patients; however, patients who were missing demographic data $(\mathrm{n}=36[2.5 \%])$, reported a history of colorectal cancer $(n=20[1.4 \%])$, or reported a history of colorectal problems $(n=406$ [28.3\%]) were excluded from the analysis, resulting in a working sample size of 975 . Study methods, including patient recruitment methods, are discussed more fully elsewhere. ${ }^{34-37}$ The overall study recruitment rate was $81 \%$. Participants and those who refused to participate were similar in sex but differed in age. Older patients were more likely to participate than younger patients $(68 \%$ of patients aged 50-59 years agreed to participate compared with $90 \%$ of those aged $60-69$ years and $85 \%$ of those aged $\geq 70$ years). Those who consented to participate in the study were asked to complete a survey that took approximately 15 minutes. The survey asked about their health and medical history, their satisfaction with care provided in the practice, and their recollection of receipt or recommendation for preventive cancer screening for CRC in addition to breast and cervical cancers for women and prostate cancer for men. The patient survey was the source of data for CRC screening and recommendations for screening, sex, marital status, education level, race, smoking status, family history of CRC (first-degree relative), age, insurance, and body mass index (BMI). Each patient also consented to have their medical record reviewed. For all patients, nurse chart auditors from the research team noted patient's weight, length of enrollment in the practice, number of visits in the past 2 years, and medical illnesses. The medical record was the source of data for comorbidities, length of enrollment in practice, and the number of visits in the past 2 years.

In addition to the medical record review, practice managers and lead physicians completed a 46item practice information survey that solicited information regarding the practice such as patient population (eg, payer mix, race/ethnicity), number of clinicians, type of practice and ownership, years in existence, and use of electronic medical records.

\section{Statistical Analyses Variables}

\section{Screening}

We examined CRC screening using the US Preventive Services Task Force clinical considerations ${ }^{38}$ and the American Cancer Society screening recommen- 
dations ${ }^{39}$ regarding age and appropriate time interval to evaluate whether patients had been screened. The American Cancer Society recommendations are similar to the US Preventive Services Task Force recommendations with the exception of including CT colonography and fecal DNA as possible screening methods. These methods have not been included for the purposes of our analysis. Patients were considered to be up to date on their CRC screening if they reported receiving 1 of the following tests within the recommended time period from the index visit: (1) colonoscopy within 10 years; (2) sigmoidoscopy within 5 years; or (3) at-home FOBT within the past year. Because patients may have been referred by other physicians, screening was assessed by patient survey. Patients were asked, "A colonoscopy is an examination where a tube is inserted into the rectum to view the ENTIRE bowel for signs of cancer; some medication is usually given through a needle in your arm to make you sleepy and you are told to have someone drive you home. Did you have a colonoscopy in the past 10 years?" The definition of a colonoscopy was taken from the Behavioral Risk factor Surveillance Survey. Similar questions were asked for FOBT and sigmoidoscopy. Because patients and physicians were not blinded to the focus of the study, we avoided Hawthorne effects by assessing CRC screening retrospectively with the index visit considered the last visit before the date of recruitment. For each eligible patient in the practice, a binary variable was created to indicate whether CRC screening had occurred according to US Preventive Services Task Force/American Cancer Society recommendations $(0=$ no, $1=$ yes $)$.

\section{Receipt of Screening Recommendation}

A binary variable was created to indicate whether patients had received a recommendation for CRC screening $(0=$ no, $1=$ yes $)$. Patients who reported having had screening were assumed to have physician recommendations and scored as yes. ${ }^{11,31} \mathrm{In}$ addition, patients who had not received CRC screening (ie, FOBT, sigmoidoscopy, or colonoscopy) within the American Cancer Society/US Preventive Services Task Force recommended interval were asked, "If you did not have a __, has anyone in this practice ever recommended that you have one?" ( $0=$ no, $1=$ yes). Those who indicated yes were scored as yes on the receipt of screening recommendation variable.

\section{Adherence to Screening Recommendations}

A final binary variable was created to assess patient adherence to screening recommendation $(0=$ no, $1=$ yes). Patients were scored as adherent to screening recommendations if they received a recommendation and were up to date on CRC screening.

\section{Patient Characteristics}

We examined sex, marital status, education level, race, smoking status, family history of CRC (firstdegree relative), age, insurance, BMI, length of enrollment in practice, number of visits in the past 2 years, and number of comorbidities as predictors of screening. Patients were asked to select 1 of the following categories for marital status: married, single, divorced, widowed, or other. For the purposes of our analysis, we condensed the categories to married versus unmarried. Family history of CRC was assessed using the following question: "Do you have any close blood relatives (parent, brother, sister, child) who have or had the following cancers? (choose all that apply)" with response choices breast cancer, CRC, prostate cancer, other cancer. Comorbidities of interest included diabetes with or without end organ damage, hypertension, and heart disease (defined as myocardial infarction, peripheral vascular disease, stroke, chronic heart failure, and coronary artery disease). Nurses reviewed the first visit, problem list, and past 5 years of progress notes, consult letters, and diagnostic tests in the medical record and patients were given a comorbidity score ranging from 0 to 3 depending on how many of the 3 comorbidities of interest were documented in the medical record. We also included indicator variables for the year of recruitment and whether the patient was recruited from an intervention or control group practice.

\section{Practice Characteristics}

Number of clinicians, practice ownership, use of an electronic medical record, practice type, average number of years the practices had been in existence, and whether the practice provides on-site flexible sigmoidoscopy were reported as descriptors of the sample practices.

\section{Analysis}

Descriptive statistics, including proportions for all categorical descriptors and means with SDs for 
continuous descriptors, were calculated to describe both the study population of patients as well as the practices. Subgroups of patients were defined by categories of each patient characteristic. Frequencies and percentages of (1) those who have received a recommendation; and (2) those up to date on CRC screening are reported within each subgroup.

Generalized estimating equations were used to model both bivariate and multivariate regressions investigating associations between the screening and/or recommendation status and the patient predictors of interest, including sex, age, etc. This analysis produces regression coefficients that may be interpreted as population-averaged effects. The models, using logit links and working correlation matrices with sandwich estimators to estimate SEs, modeled the $\log$ odds of screening/recommendation as a function of the patient predictors. Two separate sets of analyses were performed: (1) comparing patients who received recommendations for screening versus those who did not; and (2) out of those who received recommendations, comparing those who actually were screened versus those who were not. In the last analysis, by assuming that anyone who was screened received a screening recommendation and combining those patients with the population of patients who were not screened but received a screening recommendation, we were able to focus on what patient characteristics predicted patient adherence with screening recommendations. The SAS/STAT software (SAS system for Windows, Version 9.1.3) was used for all statistical analyses with the Genmod procedure for the generalized estimating equations using a backward stepwise regression technique with an exit $\alpha$ level of $(P=.1)$.

\section{Results}

The majority of the 25 practices in this study were group practices $(88 \%)$ with an average of $4.3(\mathrm{SD}=$ 3.1) clinicians per practice. Most practices were physician-owned ( $88 \%$ ) by family medicine physicians $(80 \%)$. The average practice had been in existence 11 years $(\mathrm{SD}=8.5)$. Less than half of practices (44\%) used electronic medical records. Five of 25 practices (20\%) had on-site flexible sigmoidoscopy available.

Table 1 describes the 975 patients recruited for the study. The average patient eligible for this study in the practices was 63.0 years $(\mathrm{SD}=9.8)$. Most were white (71\%), married (63\%), nonsmok-
Table 1. Characteristics of the Study Sample*

\begin{tabular}{|c|c|c|}
\hline Characteristics & Total N & Percent \\
\hline Total sample & 975 & 100.0 \\
\hline \multicolumn{3}{|l|}{ Sex } \\
\hline Male & 380 & 39.0 \\
\hline Female & 595 & 61.0 \\
\hline \multicolumn{3}{|l|}{ Age } \\
\hline $50-64$ years & 627 & 64.3 \\
\hline$\geq 65$ years & 348 & 35.7 \\
\hline \multicolumn{3}{|l|}{ Marital status } \\
\hline Married & 611 & 62.7 \\
\hline Not married & 364 & 37.3 \\
\hline \multicolumn{3}{|l|}{ Education level } \\
\hline Less than college & 586 & 60.1 \\
\hline $\begin{array}{l}\text { College degree or graduate } \\
\text { school }\end{array}$ & 389 & 39.9 \\
\hline \multicolumn{3}{|l|}{ Race } \\
\hline White & 694 & 71.2 \\
\hline Black & 177 & 18.2 \\
\hline Hispanic & 61 & 6.3 \\
\hline Other & 43 & 4.4 \\
\hline \multicolumn{3}{|l|}{ Smoking status } \\
\hline Nonsmoker & 866 & 88.8 \\
\hline Current smoker & 109 & 11.9 \\
\hline \multicolumn{3}{|l|}{$\begin{array}{l}\text { Family history of colorectal } \\
\text { cancer }\end{array}$} \\
\hline Positive family history & 86 & 8.8 \\
\hline Negative family history & 889 & 91.2 \\
\hline \multicolumn{3}{|l|}{ Insurance } \\
\hline Medicare & 330 & 33.9 \\
\hline Medicaid & 54 & 5.5 \\
\hline Private & 503 & 51.6 \\
\hline Other or none & 88 & 9.0 \\
\hline
\end{tabular}

${ }^{*}$ We recruited 1437 patients; however, patients who were missing data for any one of these characteristics or who reported a history of colorectal cancer or colorectal problems were removed from the analysis, resulting in a working sample size of 975 .

ers $(89 \%)$, had attended at least high school or some college $(89 \%)$, and had private $(52 \%)$ or Medicare insurance (34\%). Nine percent of patients reported a family history of CRC.

Overall, $59 \%$ of patients $(n=575)$ reported being up to date on CRC screening, whereas $82 \%$ of patients $(\mathrm{n}=799)$ reported having at least received a recommendation for CRC screening. Table 2 provides bivariate results of predictors of screening recommendation and adherence to screening recommendation for patients. Male sex $(P=.0127)$, being married $(P=.0221)$, higher education $(P=.0034)$, having health insurance other than Medicaid $(P=.0247)$, and being a nonsmoker $(P=.0011)$ were significant 
Table 2. Receipt of and Adherence to Physician Recommendations for Colorectal Cancer Screening: Bivariate Results

\begin{tabular}{|c|c|c|c|c|c|c|}
\hline \multirow{3}{*}{$\begin{array}{l}\text { Study Population } \\
\text { Variable }\end{array}$} & \multicolumn{3}{|c|}{ Received Physician Recommendations } & \multicolumn{3}{|c|}{ Adherence to Physician Recommendations } \\
\hline & \multicolumn{3}{|c|}{ All Patients $\mathrm{n}=975(100 \%)$} & \multicolumn{3}{|c|}{ Recommended Patients n $=799(82 \%)$} \\
\hline & $\mathrm{N}$ & $\begin{array}{l}\text { No. (\%) Screened } \\
\text { or Recommended }\end{array}$ & $\begin{array}{l}\text { Bivariate } \\
P \text { Value }\end{array}$ & $\mathrm{N}$ & No. (\%) Screened & $\begin{array}{l}\text { Bivariate } \\
P \text { Value }\end{array}$ \\
\hline Sex & & & .013 & & & .442 \\
\hline Male & 380 & $326(85.8)$ & & 326 & $239(73.3)$ & \\
\hline Female & 595 & 47. (79.5) & & 473 & $335(70.8)$ & \\
\hline Age & & & .624 & & & $<.0001$ \\
\hline $50-64$ years & 627 & $511(84.1)$ & & 511 & $337(65.9)$ & \\
\hline$\geq 65$ years & 348 & $288(82.8)$ & & 288 & $237(82.3)$ & \\
\hline Marital status & & & .022 & & & .0002 \\
\hline Married & 611 & $514(84.1)$ & & 514 & $392(76.3)$ & \\
\hline Unmarried & 364 & $285(78.3)$ & & 285 & $182(63.9)$ & \\
\hline Education level & & & .003 & & & .064 \\
\hline Less than college & 586 & $463(79.0)$ & & 463 & $321(69.3)$ & \\
\hline $\begin{array}{l}\text { College or graduate } \\
\text { school }\end{array}$ & 389 & $336(86.4)$ & & 336 & $253(75.3)$ & \\
\hline Race & & & .183 & & & .477 \\
\hline Black & 177 & $140(79.1)$ & & 140 & $97(69.3)$ & \\
\hline Hispanic & 61 & $47(77.1)$ & & 47 & $38(80.9)$ & \\
\hline Other & 43 & $32(74.4)$ & & 32 & $22(68.8)$ & \\
\hline White & 694 & $580(83.6)$ & & 580 & 417 (71.9) & \\
\hline Smoking status & & & .001 & & & $<.0001$ \\
\hline Nonsmoker & 866 & $722(83.4)$ & & 722 & $539(74.7)$ & \\
\hline Smoker & 109 & 77 (70.6) & & 77 & $35(45.5)$ & \\
\hline $\begin{array}{l}\text { Family history of } \\
\text { colorectal cancer }\end{array}$ & & & .459 & & & .074 \\
\hline No family history & 889 & $726(81.7)$ & & 726 & $515(70.9)$ & \\
\hline Family history & 86 & $73(84.9)$ & & 73 & $59(80.8)$ & \\
\hline Insurance & & & .025 & & & $<.0001$ \\
\hline Medicare & 330 & $267(80.9)$ & & 267 & $218(81.7)$ & \\
\hline Medicaid & 54 & $43(79.6)$ & & 43 & $21(48.8)$ & \\
\hline Private & 503 & $426(84.7)$ & & 426 & $290(68.1)$ & \\
\hline Other or none & 88 & $63(71.6)$ & & 63 & $45(71.4)$ & \\
\hline Body mass index & & & .463 & & & .024 \\
\hline Normal & 323 & $265(82.0)$ & & 265 & $202(76.2)$ & \\
\hline Overweight & 370 & $297(80.3)$ & & 297 & $197(66.3)$ & \\
\hline Obese & 282 & $237(84.0)$ & & 237 & $175(73.8)$ & \\
\hline $\begin{array}{l}\text { Length of time as a } \\
\text { patient }\end{array}$ & & & .745 & & & .628 \\
\hline$<5$ years & 526 & $433(82.3)$ & & 433 & $308(71.1)$ & \\
\hline$\geq 5$ years & 449 & $366(81.5)$ & & 366 & $266(72.7)$ & \\
\hline $\begin{array}{l}\text { Number of visits in } \\
\text { past } 2 \text { years }\end{array}$ & & & .523 & & & .817 \\
\hline$<8$ visits & 657 & $542(82.5)$ & & 542 & $388(71.6)$ & \\
\hline$\geq 8$ visits & 318 & $257(80.8)$ & & 257 & $186(72.4)$ & \\
\hline Comorbidity score & & & .530 & & & .711 \\
\hline 0 & 93 & $77(82.8)$ & & 77 & $58(75.3)$ & \\
\hline 1 & 244 & $193(79.1)$ & & 193 & $133(68.9)$ & \\
\hline 2 & 352 & $295(83.8)$ & & 295 & $213(72.2)$ & \\
\hline 3 & 286 & $234(81.8)$ & & 234 & $170(72.7)$ & \\
\hline
\end{tabular}


Table 3. Receipt of and Adherence to Physician Recommendations for Colorectal Cancer Screening: Multivariate Results Using Backward Stepwise Regression Including Adjusted OR*

\begin{tabular}{|c|c|c|}
\hline \multirow{3}{*}{$\begin{array}{l}\text { Study Population } \\
\text { Variable }\end{array}$} & Received Physician Recommendations & Adherence to Physician Recommendations \\
\hline & All Patients $(\mathrm{n}=975)$ & Recommended Patients $(\mathrm{n}=799)$ \\
\hline & $\begin{array}{c}\text { Multivariate }+ \text { OR }(95 \% \text { CI) } \\
\text { Wald } P \text { Value }\end{array}$ & $\begin{array}{c}\text { Multivariate }+ \text { OR }(95 \% \text { CI }) \\
\text { Wald } P \text { Value }\end{array}$ \\
\hline Sex & 1.465 & - \\
\hline$(1 \mathrm{df})$ & $(1.013-2.117)$ & \\
\hline Male versus female & .0425 & \\
\hline Age & - & 0.397 \\
\hline$(1 \mathrm{df})$ & & $(0.270-0.585)$ \\
\hline $50-64$ years versus $\geq 65$ years & & $<.0001$ \\
\hline Marital status & - & 1.972 \\
\hline$(1 \mathrm{df})$ & & $(1.603-2.421)$ \\
\hline Married versus unmarried & & $<.0001$ \\
\hline Education level & 0.658 & 0.682 \\
\hline$(1 \mathrm{df})$ & $(0.450-0.963)$ & $(0.477-0.976)$ \\
\hline $\begin{array}{l}\text { Less than college versus college or } \\
\text { graduate school }\end{array}$ & .0311 & .0365 \\
\hline Race & - & 1.434 \\
\hline$(3 \mathrm{df})$ & & $(0.949-2.167)$ \\
\hline Black versus white & & .0871 \\
\hline Hispanic versus white & & 2.315 \\
\hline & & $(1.072-4.997)$ \\
\hline & & .0325 \\
\hline Other versus white & & 0.958 \\
\hline & & $(0.446-2.059)$ \\
\hline & & .9128 \\
\hline Family history of colorectal cancer & 0.677 & 0.556 \\
\hline$(1 \mathrm{df})$ & $(0.426-1.075)$ & $(0.291-1.062)$ \\
\hline No family history versus family history & .0979 & .0754 \\
\hline Smoking status & 1.876 & 2.592 \\
\hline$(1 \mathrm{df})$ & $(1.240-2.840)$ & $(1.517-4.430)$ \\
\hline Nonsmoker versus smoker & .0029 & .0005 \\
\hline
\end{tabular}

Body mass index, insurance, comorbidity score, number of visits in the last 2 years, and length of time in the practice had a $P$ value of $>.10$ for both models.

*Adjusted for use of an electronic medical record, intervention status, year of the study, and variables as shown in the table. $\dagger$ Multivariate models created using backward stepwise regression with an exit $\alpha$ level of 0.10 .

—, eliminated from multivariate model using backward stepwise regression; CI, confidence interval; OR, odds ratio.

predictors of receiving a recommendation for CRC screening. Of those patients who were recommended for screening, predictors of whether they received screening included being married $(P=.0002)$, being a nonsmoker $(P<.0001)$, having a BMI in the normal or obese categories $(P=.0242)$, having Medicare insurance $(P<.0001)$, and being older $(P<.0001)$. Sex, education level, race, family history of CRC, length of time as a patient in the practice, number of visits in the past 2 years, and the comorbidity score did not affect whether patients adhered to screening recommendations.
Table 3 contains significance of the predictors using multivariate models. For all patients, sex, education, and smoking remained significant predictors of which patients received a recommendation that they be screened. The odds of receiving a recommendation were greater for men (OR, 1.465) and nonsmokers (OR, 1.876). Patients with less than collegelevel education were less likely to receive a recommendation (OR, 0.658). Marital status and insurance were no longer significant independent predictors of receipt of physician recommendations in multivariate analysis. Variables that were significant 
predictors of adherence to screening recommendations in the bivariate models remained significant in the multivariate model with the exception of insurance and BMI. In addition, education level was a significant predictor of adherence to recommendations with patients with less than a college education being less likely to adhere (OR, 0.682). Hispanic patients were also more likely to adhere to recommendations as compared with white patients (OR, 2.315).

\section{Discussion}

Consistent with previous studies ${ }^{20,40,41}$ generated in academic ${ }^{14,17}$ and integrated healthcare systems, ${ }^{42,43}$ we found that patients of community and academic practices with a family history of CRC were likely to receive and adhere to physician recommendations. This study also found, however, important mismatches between recommendation and adherence in community and academic primary care practices.

First, our findings point to a potential role for interpersonal relationships in enhancing CRC screening. We found that unmarried patients were less likely to adhere to CRC screening recommendations. Bazargan and colleagues ${ }^{44}$ also found that married or partnered patients were more likely to complete CRC screening in a study of underserved black and Hispanic urban minority populations. Our findings support that interpersonal relationships impact CRC screening decision-making ${ }^{45}$ and highlight the need to increase outreach to unpartnered patients to facilitate CRC screening and ensure adherence.

Like Shokar et al, ${ }^{17}$ we found that men were more likely to be recommended for CRC screening. However, our study found that despite receiving recommendations more often, men were not more likely to adhere to screening recommendations. Our results differ from those found in 2 large national studies ${ }^{8,40}$ and may be due to differences in the study setting.

We found no differences in screening recommendations to patients of various races, but Hispanic patients in our study were more likely to adhere to CRC screening recommendations than white patients. This is in contrast to previous findings that Hispanics are less likely to be screened for CRC. ${ }^{18,46}$ Our result may be explained in part by previous findings that Hispanics are more likely to over report CRC screening ${ }^{47}$ or, perhaps, may be a result of small sample size because Hispanics represented only a small proportion of our patient sample.

Finally, we identified patients not previously highlighted in the literature as having lower adherence to physician recommendations: younger patients ( $<70$ years). This may be because younger patients (aged 50-69 years) who are in better health than older patients have fewer opportunities to interact with physicians and therefore have fewer opportunities for CRC screening to be addressed and encouraged. For example, younger patients not yet eligible for Medicare may have higher copays for office visits and CRC screening, which have been shown to decrease screening rates. ${ }^{48,49}$ These patients may also feel less vulnerable to developing $\mathrm{CRC}$ and, therefore, delay screenings. ${ }^{50}$ However, younger patients are more likely to be diagnosed with late-stage $\mathrm{CRC}^{51}$ and they are most likely to reap extended benefits from preventive screening examinations. ${ }^{52}$ Our finding highlights a need for physicians to direct not only CRC recommendations toward this age group, but also a need to rigorously encourage these patients to adhere to recommendations.

Overall, we were encouraged that the average rates reported for receiving physician recommendations and adhering to recommendations were higher than those reported in other survey studies. ${ }^{8,11,12,17,18,53}$ However, because patients were approached face to face before physician visits, they may have overreported receipt of recommendations and screenings due to social desirability, ${ }^{54}$ yet we found in a previous study of this population relatively high concordance between self-report and chart audit for CRC screening (76\%-83\% agreement) and recommendations for CRC screening (68\%). ${ }^{35}$ Therefore, we are confident that the rates reported are accurate and reflect the experience of patients in this sample.

This study has several limitations to consider. First, our sample included mostly white, married, insured, and highly educated patients in New Jersey primary care practices. Therefore, the results may not be generalized to other populations or settings. Our relatively homogeneous population and small sample size may not have allowed us to detect differences by race or insurance status found by other studies. Second, patients in our sample were recruited from waiting rooms and represent a 
population that actually visits the doctor, potentially resulting in a selection bias toward more health-conscious patients and data obtained was retrospective. Third, patients who were up to date in CRC screening were assumed to have received physician-initiated recommendations, so those who asked their physicians to refer them for CRC screening may have been misclassified. For example, patients with a family history of CRC may have requested CRC screening tests. Fourth, concordance between patient-reported and chart-documented history of CRC and colorectal problems was $78 \% .{ }^{35}$ Because patients were slightly more likely to report a history and only $5 \%$ of patients who did not report a history of CRC or colorectal problems had a chart-documented history, we elected to use patient-reported histories. This may have caused us to exclude some patients unnecessarily. Finally, we did not differentiate screening from diagnostic procedures. Testing for diagnostic reasons may have biased our results toward overstating adherence rates in some patients at higher risk of CRC who develop symptoms such as patients with a family history or comorbid diseases (eg, diabetes) at the same time as biasing our results toward the null in others (eg, smokers).

In summary, this study suggests that a potentially fruitful strategy to further increase CRC screening rates in community and academic settings is for primary care physicians to systematically recommend screening to all patients who might benefit. We know that physician predictions of patient treatment adherence are inaccurate for a number of chronic illnesses. ${ }^{5-57}$ Therefore, it is important for physicians to make CRC screening recommendations systematically, yet there is little evidence-based information that outlines best practices for implementing such recommendations (eg, physician-patient conversation with decision aids vs use of patient registries with reminder systems vs use of a physician extender [ie, nurse practitioner for patient education]). We, therefore, also suggest that in addition to increasing physician recommendation, it is important to generate further prospective research focused on dissemination to examine feasibility, efficacy, and cost-effectiveness of implementing various physician recommendation mechanisms in community and academic settings.

\section{References}

1. Jemal A, Siegel R, Xu J, Ward E. Cancer statistics, 2010. CA Cancer J Clin 2010;60:277-300.

2. US Cancer Statistics Working Group. United States cancer statistics: 1999-2008 incidence and mortality web-based report. Atlanta, GA: US Department of Health and Human Services, Centers for Disease Control and Prevention and National Cancer Institute; 2012.

3. Siegel R, Naishadham D, Jemal A. Cancer statistics, 2012. CA Cancer J Clin 2012;62:10-29.

4. American Cancer Society. Colorectal cancer facts \& figures 2011-2013. Atlanta, GA: American Cancer Society; 2011.

5. Mandel JS, Church TR, Bond JH, Ederer F, Geisser MS, Mongin SJ, et al. The effect of fecal occultblood screening on the incidence of colorectal cancer. N Engl J Med 2000;343:1603-7.

6. Newcomb PA, Norfleet RG, Storer BE, Surawicz TS, Marcus PM. Screening sigmoidoscopy and colorectal cancer mortality. J Natl Cancer Inst 1992;84: 1572-5.

7. Klabunde CN, Lanier D, Meissner HI, Breslau ES, Brown ML. Improving colorectal cancer screening through research in primary care settings. Med Care 2008;46(suppl 1):S1-4.

8. Brawarsky P, Brooks DR, Mucci LA, Wood PA. Effect of physician recommendation and patient adherence on rates of colorectal cancer testing. Cancer Detect Prev 2004;28:260-8.

9. Gilbert A, Kanarek N. Colorectal cancer screening: physician recommendation is influential advice to Marylanders. Prev Med 2005;41:367-79.

10. Levy BT, Dawson J, Hartz AJ, James PA. Colorectal cancer testing among patients cared for by Iowa family physicians. Am J Prev Med 2006;31:193-201.

11. Wee CC, McCarthy EP, Phillips RS. Factors associated with colon cancer screening: the role of patient factors and physician counseling. Prev Med 2005;41:23-9.

12. DuBard CA, Schmid D, Yow A, Rogers AB, Lawrence WW. Recommendation for and receipt of cancer screenings among medicaid recipients 50 years and older. Arch Intern Med 2008;168:2014-21.

13. Hawley ST, Volk RJ, Krishnamurthy P, Jibaja-Weiss M, Vernon SW, Kneuper S. Preferences for colorectal cancer screening among racially/ethnically diverse primary care patients. Med Care 2008;46(suppl 1):S10-6.

14. Janz NK, Lakhani I, Vijan S, Hawley ST, Chung LK, Katz SJ. Determinants of colorectal cancer screening use, attempts, and non-use. Prev Med 2007;44:452-8.

15. Matthews BA, Nattinger AB, Venkatesan T, Shaker R. Colorectal cancer screening among midwestern community-based residents: indicators of success. J Community Health 2007;32:103-20. 
16. McQueen A, Tiro JA, Vernon SW. Construct validity and invariance of four factors associated with colorectal cancer screening across gender, race, and prior screening. Cancer Epidemiol Biomarkers Prev 2008;17:2231-7.

17. Shokar NK, Nguyen-Oghalai T, Wu H. Factors associated with a physician's recommendation for colorectal cancer screening in a diverse population. Fam Med 2009;41:427-33.

18. James TM, Greiner KA, Ellerbeck EF, Feng C, Ahluwalia JS. Disparities in colorectal cancer screening: a guideline-based analysis of adherence. Ethn Dis 2006;16:228-33.

19. Sewitch MJ, Fournier C, Dawes M, Yaffe M, Snell L, Roper M, et al. Do physician recommendations for colorectal cancer screening differ by patient age? Can J Gastroenterol 2007;21:435-8.

20. Felsen CB, Piasecki A, Ferrante JM, Ohman-Strickland PA, Crabtree BF. Colorectal cancer screening among primary care patients: does risk affect screening behavior? J Community Health 2011;36:605-11.

21. Kelly KM, Dickinson SL, Degraffinreid CR, Tatum CM, Paskett ED. Colorectal cancer screening in 3 racial groups. Am J Health Behav 2007;31:502-13.

22. Natale-Pereira A, Marks J, Vega M, Mouzon D, Hudson SV, Salas-Lopez D. Barriers and facilitators for colorectal cancer screening practices in the Latino community: perspectives from community leaders. Cancer Control 2008;15:157-65.

23. Dulai GS, Farmer MM, Ganz PA, Bernaards CA, Qi $\mathrm{K}$, Dietrich AJ, et al. Primary care provider perceptions of barriers to and facilitators of colorectal cancer screening in a managed care setting. Cancer 2004;100:1843-52.

24. Guerra CE, Schwartz JS, Armstrong K, Brown JS, Halbert CH, Shea JA. Barriers of and facilitators to physician recommendation of colorectal cancer screening. J Gen Intern Med 2007;22:1681-8.

25. Friedman M, Borum ML. Colorectal cancer screening of African Americans by internal medicine resident physicians can be improved with focused educational efforts. J Natl Med Assoc 2007;99:1010-2.

26. Glanz K, Steffen AD, Taglialatela LA. Effects of colon cancer risk counseling for first-degree relatives. Cancer Epidemiol Biomarkers Prev 2007;16: 1485-91.

27. Klabunde CN, Lanier D, Breslau ES, Zapka JG, Fletcher RH, Ransohoff DF, et al. Improving colorectal cancer screening in primary care practice: innovative strategies and future directions. J Gen Intern Med 2007;22:1195-205.

28. Lane DS, Messina CR, Cavanagh MF, Chen JJ. A provider intervention to improve colorectal cancer screening in county health centers. Med Care 2008; 46(suppl 1):S109-16.

29. Patel P, Forjuoh SN, Avots-Avotins A, Patel T. Identifying opportunities for improved colorectal cancer screening in primary care. Prev Med 2004;39: 239-46.

30. Yabroff KR, Klabunde CN, Myers R, Brown ML. Physician recommendations for follow-up of positive fecal occult blood tests. Med Care Res Rev 2005;62: 79-110.

31. Ferrante JM, Chen PH, Crabtree BF, Wartenberg D. Cancer screening in women: body mass index and adherence to physician recommendations. Am J Prev Med 2007;32:525-31.

32. Crabtree BF, Miller WL, Stange KC. Understanding practice from the ground up. J Fam Pract 2001; 50:881-7.

33. Stroebel C, McDaniel R, Crabtree B, Miller W, Nutting P, Stange K. How complexity science can inform a reflective process for improvement in primary care practices. Joint Commission Journal on Quality and Patient Safety 2005;31:438-46.

34. Felsen CB, Shaw EK, Ferrante JM, Lacroix LJ, Crabtree BF. Strategies for in-person recruitment: lessons learned from a New Jersey primary care research network (NJPCRN) study. J Am Board Fam Med 2010;23:523-33.

35. Ferrante JM, Ohman-Strickland P, Hahn KA, Hudson SV, Shaw EK, Crosson JC, et al. Self-report versus medical records for assessing cancer-preventive services delivery. Cancer Epidemiol Biomarkers Prev 2008;17:2987-994.

36. Hudson SV, Hahn KA, Ohman-Strickland P, Cunningham RS, Miller SM, Crabtree BF. Breast, colorectal and prostate cancer screening for cancer survivors and non-cancer patients in community practices. Journal of General Internal Medicine 2009;24(suppl 2):S487-90.

37. Strickland PAO, Hudson SV, Piasecki A, Hahn K, Cohen D, Orzano AJ, et al. Features of the Chronic Care Model (CCM) associated with behavioral counseling and diabetes care in community primary care. J Am Board Fam Med 2010;23:295-305.

38. US Preventive Services Task Force. Screening for colorectal cancer: recommendation and rationale. Am Fam Physician 2002;66:2287-90.

39. Smith RA, Cokkinides V, Eyre HJ. American Cancer Society guidelines for the early detection of cancer, 2004. CA Cancer J Clin 2004;54:41-52.

40. Meissner HI, Breen N, Klabunde CN, Vernon SW. Patterns of colorectal cancer screening uptake among men and women in the United States. Cancer Epidemiol Biomarkers Prev 2006;15:389-94.

41. Sifri R, Myers R, Hyslop T, Turner B, Cocroft J, Rothermel T, et al. Use of cancer susceptibility testing among primary care physicians. Clin Genet 2003;64:355-60.

42. Partin MR, Noorbaloochi S, Grill J, Burgess DJ, van Ryn M, Fisher DA, et al. The interrelationships between and contributions of background, cognitive, and environmental factors to colorectal cancer 
screening adherence. Cancer Causes Control 2010; 21:1357-68.

43. Yano EM, Soban LM, Parkerton PH, Etzioni DA. Primary care practice organization influences colorectal cancer screening performance. Health Serv Res 2007;42:1130-49.

44. Bazargan M, Ani C, Bazargan-Hejazi S, Baker RS, Bastani R. Colorectal cancer screening among underserved minority population: discrepancy between physicians' recommended, scheduled, and completed tests. Patient Educ Couns 2009;76:240-7.

45. Manne S, Etz RS, Hudson SV, Medina-Forrester A, Boscarino JA, Bowen DJ, et al. A qualitative analysis of couples' communication regarding colorectal cancer screening using the Interdependence Model. Patient Educ Couns 2012;87:18-22.

46. Shi L, Lebrun LA, Zhu J, Tsai J. Cancer screening among racial/ethnic and insurance groups in the United States: a comparison of disparities in 2000 and 2008. J Health Care Poor Underserved 2011;22: 945-61.

47. Shokar NK, Vernon SW, Carlson CA. Validity of self-reported colorectal cancer test use in different racial/ethnic groups. Fam Pract 2011;28:683-8.

48. Varghese RK, Friedman C, Ahmed F, Franks AL, Manning M, Seeff LC. Does health insurance coverage of office visits influence colorectal cancer testing? Cancer Epidemiol Biomarkers Prev 2005;14: 744-7.

49. Wharam JF, Graves AJ, Landon BE, Zhang F, Soumerai SB, Ross-Degnan D. Two-year trends in colorectal cancer screening after switch to a highdeductible health plan. Med Care 2011;49:865-71.
50. Weinberg DS, Miller S, Rodoletz M, Egleston B, Fleisher L, Buzaglo J, et al. Colorectal cancer knowledge is not associated with screening compliance or intention. J Cancer Educ 2009;24:225-32.

51. Campbell RJ, Ferrante JM, Gonzalez EC, Roetzheim RG, Pal N, Herold A. Predictors of advanced stage colorectal cancer diagnosis: results of a population-based study. Cancer Detect Prev 2001;25: 430-8.

52. Resnick B, McLeskey SW. Cancer screening across the aging continuum. Am J Manag Care 2008;14: 267-6.

53. Sewitch MJ, Fournier C, Ciampi A, Dyachenko A. Adherence to colorectal cancer screening guidelines in Canada. BMC Gastroenterol 2007;7:39.

54. Rauscher GH, Johnson TP, Cho YI, Walk JA. Accuracy of self-reported cancer-screening histories: a meta-analysis. Cancer Epidemiol Biomarkers Prev 2008; 17:748-57.

55. Phillips LA, Leventhal EA, Leventhal H. Factors associated with the accuracy of physicians' predictions of patient adherence. Patient Educ Couns 2011;85:461-7.

56. Wagner JH, Justice AC, Chesney M, Sinclair G, Weissman S, Rodriguez-Barradas M. Patient- and provider-reported adherence: toward a clinically useful approach to measuring antiretroviral adherence. J Clin Epidemiol 2001;54(suppl 1):S91-8.

57. Zeller A, Taegtmeyer A, Martina B, Battegay E, Tschudi P. Physicians' ability to predict patients' adherence to antihypertensive medication in primary care. Hypertens Res 2008;31:1765-71. 